\title{
TLR3 signaling is either protective or pathogenic for the development of Theiler's virus-induced demyelinating disease depending on the time of viral infection
}

Young-Hee Jin ${ }^{1}$, Tomoki Kaneyama ${ }^{2}$, Min Hyung Kang ${ }^{1}$, Hyun Seok Kang ${ }^{1}$, Chang-Sung Koh ${ }^{3^{*}}$ and Byung S Kim ${ }^{1 *}$

\begin{abstract}
Background: We have previously shown that toll-like receptor 3 (TLR3)-mediated signaling plays an important role in the induction of innate cytokine responses to Theiler's murine encephalomyelitis virus (TMEV) infection. In addition, cytokine levels produced after TMEV infection are significantly higher in the glial cells of susceptible SJL mice compared to those of resistant C57BL/6 mice. However, it is not known whether TLR3-mediated signaling plays a protective or pathogenic role in the development of demyelinating disease.

Methods: SJL/J and B6;129S-T/r3 ${ }^{\text {tm } 1 F / v} / J$ (TLR3KO-B6) mice, and TLR3KO-SJL mice that TLR3KO-B6 mice were backcrossed to SJL/J mice for 6 generations were infected with Theiler's murine encephalomyelitis virus $\left(2 \times 10^{5}\right.$ PFU) with or without treatment with $50 \mu \mathrm{g}$ of poly IC. Cytokine production and immune responses in the CNS and periphery of infected mice were analyzed.

Results: We investigated the role of TLR3-mediated signaling in the protection and pathogenesis of TMEV-induced demyelinating disease. TLR3KO-B6 mice did not develop demyelinating disease although they displayed elevated viral loads in the CNS. However, TLR3KO-SJL mice displayed increased viral loads and cellular infiltration in the CNS, accompanied by exacerbated development of demyelinating disease, compared to the normal littermate mice. Late, but not early, anti-viral CD4 ${ }^{+}$and $C D 8^{+} T$ cell responses in the CNS were compromised in TLR3KO-SJL mice. However, activation of TLR3 with poly IC prior to viral infection also exacerbated disease development, whereas such activation after viral infection restrained disease development. Activation of TLR3 signaling prior to viral infection hindered the induction of protective IFN- $\gamma$-producing $\mathrm{CD}^{+}$and $\mathrm{CD} 8^{+} \mathrm{T}$ cell populations. In contrast, activation of these signals after viral infection improved the induction of IFN- $\gamma$-producing $\mathrm{CD}^{+}$and $\mathrm{CD} 8^{+} \mathrm{T}$ cells. In addition, poly IC-pretreated mice displayed elevated PDL-1 and regulatory FoxP3 ${ }^{+} \mathrm{CD}^{+} \mathrm{T}$ cells in the CNS, while poly IC-post-treated mice expressed reduced levels of PDL-1 and FoxP3 ${ }^{+} \mathrm{CD}^{+} \mathrm{T}$ cells.
\end{abstract}

Conclusions: These results suggest that TLR3-mediated signaling during viral infection protects against demyelinating disease by reducing the viral load and modulating immune responses. In contrast, premature activation of TLR3 signal transduction prior to viral infection leads to pathogenesis via over-activation of the pathogenic immune response.

Keywords: TLR3, TMEV, demyelination, CNS, T cell responses

\footnotetext{
* Correspondence: kshosei@shinshu-u.ac.jp; bskim@northwestern.edu

'Department of Microbiology-Immunology, Northwestern University Medical

School, Chicago, Illinois 60611, USA

${ }^{3}$ Biomedical Laboratory Sciences, Graduate School of Medicine, Shinshu

University, Matsumoto, Nagano 390-8621, Japan

Full list of author information is available at the end of the article
} 


\section{Background}

Toll-like receptor 3 (TLR3) recognizes double stranded RNA (dsRNA), including poly IC and viral dsRNAs. TLR3 activation induces the production of a variety of cytokines, such as IL-1 $\beta$, IL- 6 and type I interferon (IFN) [1-4]. However, the role that TLR3 activation plays in the protection from or pathogenesis of virusinduced chronic disease is still unclear. It has been reported that a dominant-negative TLR3 allele is associated with the development of herpes simplex encephalitis, suggesting that TLR3 plays a protective role in herpes simplex virus infection [5]. In addition, TLR3 appears to play a protective role against infections with West Nile virus (WNV) [6], Coxsackievirus B4 [7], and mouse cytomegalovirus [8]. However, a detrimental role of TLR3 in the induction of acute pneumonia following influenza A virus infection has also been reported [9]. In addition, several studies have indicated that TLR3mediated signals play either no role or a pathogenic role in viral diseases. For example, a recent study demonstrated that the absence of TLR3 did not alter viral pathogenesis after infection with single-stranded or double-stranded RNA viruses, such as lymphocytic choriomeningitis virus, vesicular stomatitis virus, and reovirus [10]. Furthermore, TLR3-deficient mice were more resistant to lethal WNV infection, although a TLR3mediated signal was critical for the virus to penetrate into the brain where it caused neuropathogenesis [11].

Theiler's murine encephalomyelitis virus (TMEV) is a positive sense single-stranded RNA (ssRNA) virus of the Picornaviridae family [12]. TMEV establishes a persistent CNS infection in susceptible mouse strains that results in the development of demyelinating disease, which is considered a relevant viral model for human multiple sclerosis [13-15]. It has previously been shown that TLR3 recognizes the dsRNAs generated as TMEV replication intermediates, and TLR3 is essential for the production of TMEV-induced inflammatory cytokines, such as type I IFNs $[16,17]$. TLR3 is constitutively expressed in a variety of cells, including antigen presenting cells (dendritic cells and macrophages) as well as glial cells, including microglia and astrocytes [18]. In addition, the expression level of TLR3 is upregulated following TMEV infection and its expression levels are particularly high in cells from susceptible mice $[19,20]$. Furthermore, antigen presenting cells in the periphery and glial cells in the CNS are much more permissive to TMEV infection and support viral replication better than cells from resistant mice [21,22]. The differences appear to be, in part, due to the high intrinsic activation state of NF- $\kappa$ B in cells from susceptible mice [23]. TLR3-mediated signals activate multiple NF- $\kappa \mathrm{B}$ pathways and upregulate the expression of other TLRs, such as TLR2, and following TMEV infection, these secondary TLRs contribute to the production of additional proinflammatory cytokines $[17,24]$. However, dsRNAs, including synthetic dsRNA poly IC, are recognized not only by TLR3 but also by MDA5 and PKR [16,24]. Therefore, the relative role of TLR3-mediated signaling in the development of TMEV-induced demyelinating disease remains to be determined.

In particular, the induction of strong type I IFN production, following infection with TMEV, is mediated by TLR3 and MDA5-mediated signals [16,17,24,25]. Our previous results showed that type I IFN was critical for the prevention of rapid fatal encephalitis, by controlling the viral load and the infiltration of inflammatory cells into the CNS [26]. However, type I IFN levels were significantly higher in susceptible SJL mice compared to resistant C57BL/6 mice [22]. Interestingly, type I IFNs play dichotomous roles in stimulating the immune responses, i.e., up- or down-regulating $\mathrm{T}$ cell responses, apparently depending on IFN concentration $[21,27]$. Furthermore, the time of type I IFN presence seems to be an important factor for the function of type I IFNs against viral infection [21]. Many recent studies utilized poly IC to activate TLR3 and/or MDA5-mediated signals in conjunction with viral infections and/or autoimmunity. For example, poly IC treatment of virus-infected mice resulted in a type I IFN-dependent reduction in viral loads and protection from virus-induced disease by enhancing the function of virus-specific $\mathrm{T}$ cells $[28,29]$. However, treatment with poly IC enhances the development of autoimmune diseases [30-32]. Therefore, it would be important to investigate the effects of different levels of type I IFNs that are activated via TLR3 in resistant and susceptible mice to determine its impact on the development of TMEV-induced demyelinating disease, which bears both viral and autoimmunity components.

To investigate the role of TLR3-mediated innate immune responses on the pathogenesis of TMEVinduced demyelinating disease, we utilized TLR3-deficient mice in both the resistant C57BL/6 (B6) and susceptible SJL/J backgrounds. In addition, we administered poly IC to activate TLR3-mediated signals prior to or after TMEV infection. Our results showed that TLR3deficient susceptible SJL mice accelerated the development of demyelinating disease, whereas TLR3-deficient resistant B6 mice remained disease free. The virusinfected TLR3-deficient SJL mice displayed increased cellular infiltration and an elevated viral load in the CNS. Therefore, TLR3-mediated signals are important in protecting susceptible mice from the development of TMEV-induced demyelinating disease, although TLR3mediated signals appear to play a minor role in resistant mice. However, treatment with poly IC prior to viral 
infection exacerbated disease development in susceptible mice, while treatment after viral infection somewhat ameliorated it. This observation suggests that either a premature activation or an over-activation of TLR3 signaling during early viral infection may lead to pathogenesis, perhaps through the development of a pathogenic immune response. Therefore, our current results strongly warrant caution on the use of TLR3-mediated immune interventions against chronic viral diseases and suggest careful consideration for these treatments in conjunction with the time of viral infection.

\section{Materials and methods}

Mice

SJL/J mice were purchased from the Charles River Laboratories (Charles River, MA) through the National Cancer Institute (Frederick, MD). B6; 129S-Tlr3 $3^{t m 1 F l v} / \mathrm{J}$ mice (TLR3KO-B6) were purchased from Jackson Laboratories (Bar Harbor, ME). TLR3KO-B6 mice were backcrossed to SJL/J mice for 6 generations to obtain TLR3KO-SJL mice. The absence/presence of TLR3 in TLR3KO-SJL and the littermate mice (NLM) were typed based on the electrophoresis patterns of TLR3 and neomycin resistant genes. PCR products from tail genomic DNA of NLM and TLR3KO-SJL mice were determined using PCR-based genotyping analysis established by the Jackson Laboratory (Additional file 1, Figure S1). Experimental procedures that were approved by the Animal Care and Use Committee of Northwestern University in accordance with NIH animal care guidelines were used in this study.

\section{Virus}

The BeAn and GDVII strains of TMEV were propagated in BHK-21 cells grown in DMEM medium supplemented with $7.5 \%$ donor calf serum. Viral titer was determined by plaque assay on BHK cell monolayers. The cells were incubated for 4-5 days in infection-medium (DMEM supplemented with $0.1 \%$ bovine serum albumin) with TMEV at 10 MOIs and the cell lysates were cleared by centrifugation. The cleared lysates yield 3-5 $\times$ $10^{8} \mathrm{PFU}$ and a pooled batch was used as a viral stock. If necessary the viral stock was diluted in DMEM before inoculation.

\section{Assessment of clinical signs}

Approximately $30 \mu \mathrm{l}$ of TMEV was injected into the right hemisphere of 5- to 7-week-old mice anesthetized with isofluorane. Resistant B6 and TLR3KO-B6 mice were infected with $1 \times 10^{6} \mathrm{PFU}$ and susceptible SJL and TLR3KO-SJL mice were infected with $2 \times 10^{5}$ PFU TMEV. Clinical symptoms of disease were assessed weekly on the following grading scale: grade $0=$ no clinical signs; grade $1=$ mild waddling gait; grade $2=$ moderate waddling gait and hindlimb paresis; grade $3=$ severe hind limb paralysis; grade $4=$ severe hind limb paralysis and loss of righting reflex; and grade $5=$ death.

\section{Plaque assay}

After cardiac perfusion with cold Hank's balanced salt solution (HBSS) (Mediatech), brain and spinal cords were removed. The tissues were homogenized in HBSS using a tissue homogenizer. A standard plaque assay was performed on BHK-21 cell monolayers [33]. Plaques in the BHK monolayer were visualized by staining with $0.1 \%$ crystal violet solution after fixing with methanol.

\section{Isolation of CNS-infiltrating lymphocytes}

Mice were perfused through the left ventricle with 30 $\mathrm{ml}$ of sterile HBSS. Excised brains and spinal cords were forced through wire mesh and incubated at $37^{\circ} \mathrm{C}$ for 45 $\mathrm{min}$ in $250 \mu \mathrm{g} / \mathrm{ml}$ of collagenase type 4 (Worthington). CNS-infiltrating lymphocytes were then enriched at the bottom $1 / 3$ of a continuous $100 \%$ Percoll (GE) gradient after centrifugation for $30 \mathrm{~min}$ at $27,000 \times \mathrm{g}$.

\section{Flow cytometry}

CNS-infiltrating lymphocytes were isolated and Fc receptors were blocked using $100 \mu \mathrm{l}$ of $2.4 \mathrm{G} 2$ hybridoma (ATCC) supernatant by incubating at $4^{\circ} \mathrm{C}$ for $30 \mathrm{~min}$ utes. The indicated antibodies were subsequently used

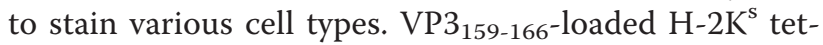
ramer labeled with PE was used to assess levels of virusspecific $\mathrm{CD}^{+} \mathrm{T}$ cells in the CNS of TMEV-infected mice. Cells were analyzed using a Becton Dickinson LSRII flow cytometer.

\section{Intracellular cytokine staining}

Freshly isolated CNS-infiltrating mononuclear cells were cultured in 96-well round bottom plates in the presence of viral or control peptides and Golgi-Plug ${ }^{\mathrm{TM}}$ (BD) for 6 $\mathrm{h}$ at $37^{\circ} \mathrm{C}$. Cells were then incubated in $100 \mu \mathrm{l}$ of $2.4 \mathrm{G} 2$ hybridoma (ATCC) supernatant for 30 minutes at $4{ }^{\circ} \mathrm{C}$ to block Fc receptors. Anti-CD8 (clone 53-6.7) antibody or anti-CD4 (clone L3T4) antibody was added, and cells were incubated for an additional 30 minutes at $4{ }^{\circ} \mathrm{C}$. After two washes, intracellular IFN- $\gamma$ staining was performed according to the manufacturer's instructions (BD) using PE-labeled rat monoclonal anti-IFN- $\gamma$ (XMG1.2) antibody. Cells were analyzed by flow cytometry.

\section{RT-PCR and real-time PCR}

Total RNA was isolated by TRIzol reagent (Invitrogen) and reverse transcribed to cDNA using Moloney murine leukemia virus reverse transcriptase (Invitrogen). The cDNAs were amplified with specific primer sets using the SYBR Green Supermix (Bio-Rad) on an iCycler (Bio- 
Rad). The sense and antisense primer sequences used for cytokines are as follows: TMEV (VP1), (5' -TGACTAAGCAGGACTATGCCTTCC-3' and 5'-CAACGAGC CACATATGCGGATTAC-3'); IL-1 $\beta$, (5'-TCATGGGATGATAACCTGCT-3' and 5'-CCCATACTTTAGGA A-GACACGGAT-3'); IFN- $\alpha$, (5'-ACCTCCTCTGACCCAGGAAG -3' and 5'-GGCTCTCCAGA-CTTC TG CTC-3'); IFN- $\beta$, (5'-CCCTATGGAGATGACGGAGA-3' and 5'-CTGTCTGCTGG-TGGAGTTGA-3'); IFN- $\gamma$, (5'ACTGGCAAAAGGATGGTGAC-3' and 5'-TGAGCTCATT-GAATGCTT GG-3'); IL-10, (5'-GCCA AGCCTTATCGGAAATGATCC-3' and 5'-AGACA-CCTTG GTCTTGGAGCTT-3'); TNF- $\alpha$, (5'-CTGTGAAGGGAATGGGTGTT-3' and 5'-GGTCACTGTCCCAGCATCTT-3'); IL-6, (5'-AGTTGCCTTCTTGGGAC TGA-3' and 5'-TCCACGATTTCCCAGAGAAC-3'); IL17, (5'-GGGGATCCATGAGTCCAGGGAGAGC-3' and 5'-CCCTCGAGTTAGGCTGCCTGGCGGA-3'); CX CL10, (5'-AAGTGCTGCCGTC-ATTTTCT-3' and 5'GTGGCAATGATCTCAACACG-3') and GAPDH, (5'AACTTTGG-CATTGTGGAAGGGCTC-3' and 5'-TG CCTGCTTCACCACCTTCTTGAT-3'). GAPDH expression served as an internal reference for normalization. Real-time PCR was performed in triplicate.

\section{Statistical analyses}

The statistical significance of the differences between experimental groups (two-tailed p value) was analyzed with the unpaired Student's t-test using the InStat Program (GraphPAD). Comparisons of the disease courses between 2 groups were also performed using the paired t-test. Values of $P<0.05$ were considered to be significant.

\section{Results}

TLR3 deficiency in resistant B6 mice does not cause demyelinating disease by BeAn but results in elevated encephalitic death by the virulent GDVII strain of TMEV It has previously been reported that TLR3 plays a critical role in TMEV-induced inflammatory cytokine and chemokine responses $[16,17]$. To examine the role of TLR3 in the development of TMEV-induced disease, we compared the development of clinical signs and viral loads in the CNS of control B6 and TLR3-deficient B6 (TLR3KO-B6) mice following infection with the BeAn strain of TMEV $\left(1 \times 10^{6} \mathrm{PFU}\right)$. Viral levels in the CNS of TLR3KO-B6 mice at 7 and 21 days post-infection (dpi) were significantly higher in the brain and spinal cord than the viral levels of the B6 control mice (Figure 1A). However, neither the B6 nor the TLR3KO-B6 mice developed detectable clinical signs of disease (data not shown). These results indicate that TLR3 signals are important in controlling TMEV loads in the CNS, although the increased viral levels did not lead to the development of demyelinating disease. Flow cytometric analysis of the CNS cells indicated that the level of mononuclear cells, including $\mathrm{T}$ cells and macrophages, that infiltrated the CNS of the TLR3KO-B6 mice were similar to those of the B6 mice at 7 dpi (Figure 1B). However, the levels of these cells in the CNS of TLR3KO-B6 mice were significantly higher than those of control B6 mice at $21 \mathrm{dpi}$. The elevated viral load in the TLR3KO mice may have caused a higher cellular infiltration into the CNS by activating higher levels of inflammatory cytokines and chemokines. To further determine the levels of virus-specific $\mathrm{CD}^{+}$and $\mathrm{CD}^{+} \mathrm{T}$ cells that infiltrated into the CNS, mononuclear cells were isolated from the CNS of TMEV-infected mice at 7 and $21 \mathrm{dpi}$, and these cells were stimulated with TMEV-specific viral epitope peptides. Subsequently, the ability of these $\mathrm{T}$ cells to produce IFN- $\gamma$ was assessed by flow cytometry after intracellular cytokine staining (Figure $1 \mathrm{C}$ ). The proportions of IFN- $\gamma$-producing, TMEVspecific $\mathrm{CD}^{+} \mathrm{T}$ cells and $\mathrm{CD} 8^{+} \mathrm{T}$ cells in the CNS were similar between TLR3KO-B6 and B6 mice.

As there were no differences in the development of TMEV BeAn-induced demyelinating disease between TLR3KO-B6 and B6 control mice, we further explored the potential differences in the susceptibility of these mice to a highly virulent GDVII strain of TMEV [34] that was administered via intraperitoneal injection (Figure 1D). After a low dose of viral infection (100 PFU), fewer than $26 \%$ of the control B6 mice developed fatal encephalitis, whereas greater than $50 \%$ of TLR3KO-B6 mice developed disease. In addition, virus-infected TLR3KO mice showed significantly higher levels of viral load in the CNS at 7 dpi compared to the infected B6 mice (Figure 1E), consistent with the differences noted in disease severity. These results indicate that TLR3mediated signaling in resistant B6 mice plays an important role in controlling viral infection, particularly for highly virulent, encephalitic strains of TMEV.

\section{TLR3-deficient SJL (TLR3KO-SJL) mice are more} susceptible to BeAn-induced demyelinating disease than SJL mice

To examine whether TLR3 plays a more prominent role in TMEV-susceptible SJL mice, we infected TLR3KO-SJL mice and normal littermates (NLM) at the $6^{\text {th }}$ generation of backcrossing to SJL/J mice with a low dose $\left(2 \times 10^{5}\right.$ PFU) of TMEV BeAn. These virusinfected mice were then assessed for the progression of demyelinating disease for $80 \mathrm{dpi}$ (Figure 2A). We chose the low dose of the virus to maximize the differences in disease development. Interestingly, TLR3KO-SJL mice showed exacerbated development of TMEVinduced demyelinating disease compared to the NLM. We further examined the viral loads in the CNS 


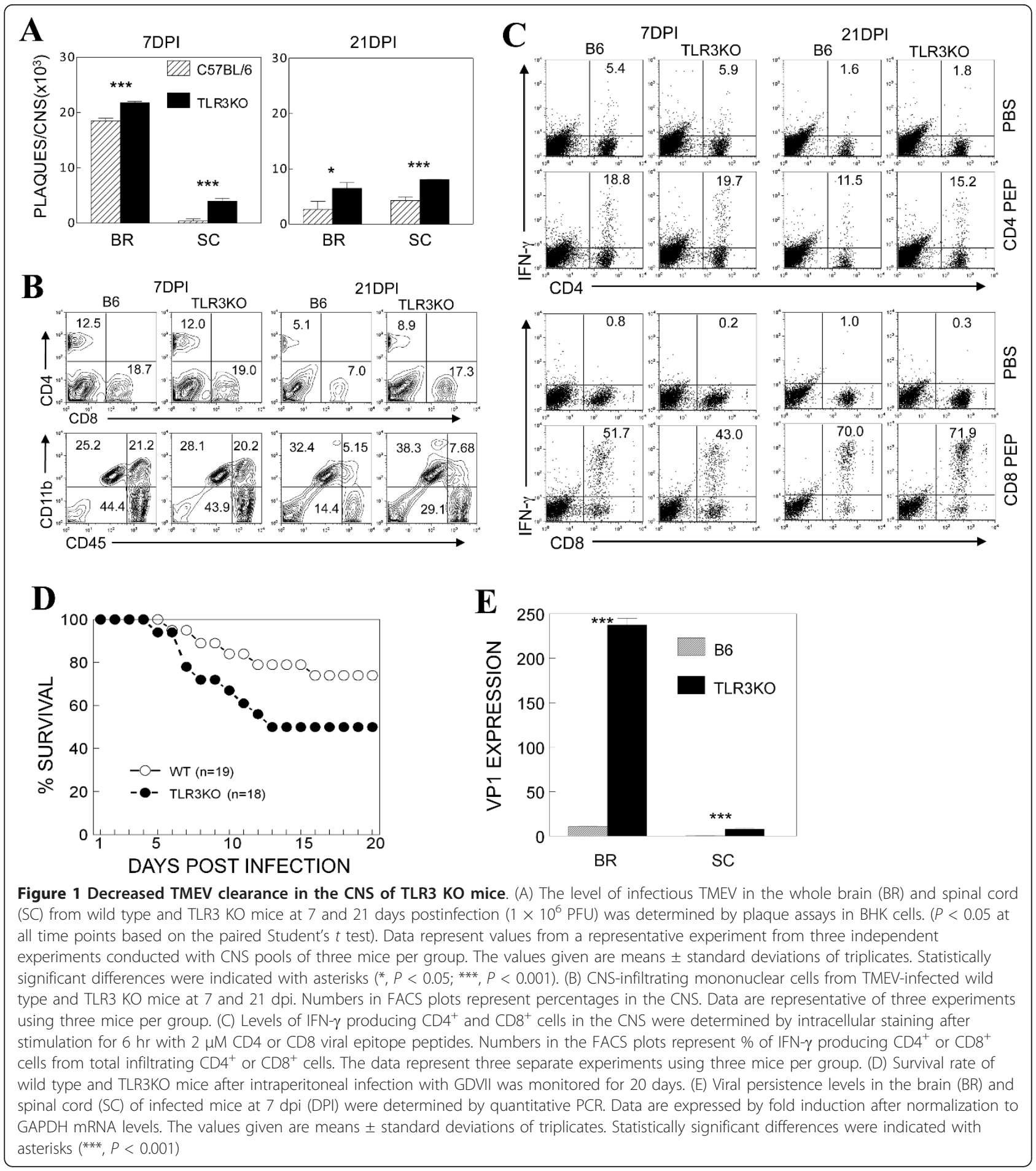

(brains and spinal cords) of both mouse groups at 7 , 21 and $50 \mathrm{dpi}$ using plaque assays (Figure 2B). The levels of infectious virus in the CNS of TLR3KO-SJL mice were significantly higher both in the brain and spinal cord compared to those for the control NLM mice. These results indicate that TLR3 signaling plays an important role in controlling viral load in the CNS and in preventing the development of TMEV-induced demyelinating disease following infection with a less virulent BeAn strain in mice of the susceptible SJL background, unlike mice of the resistant B6 background. 


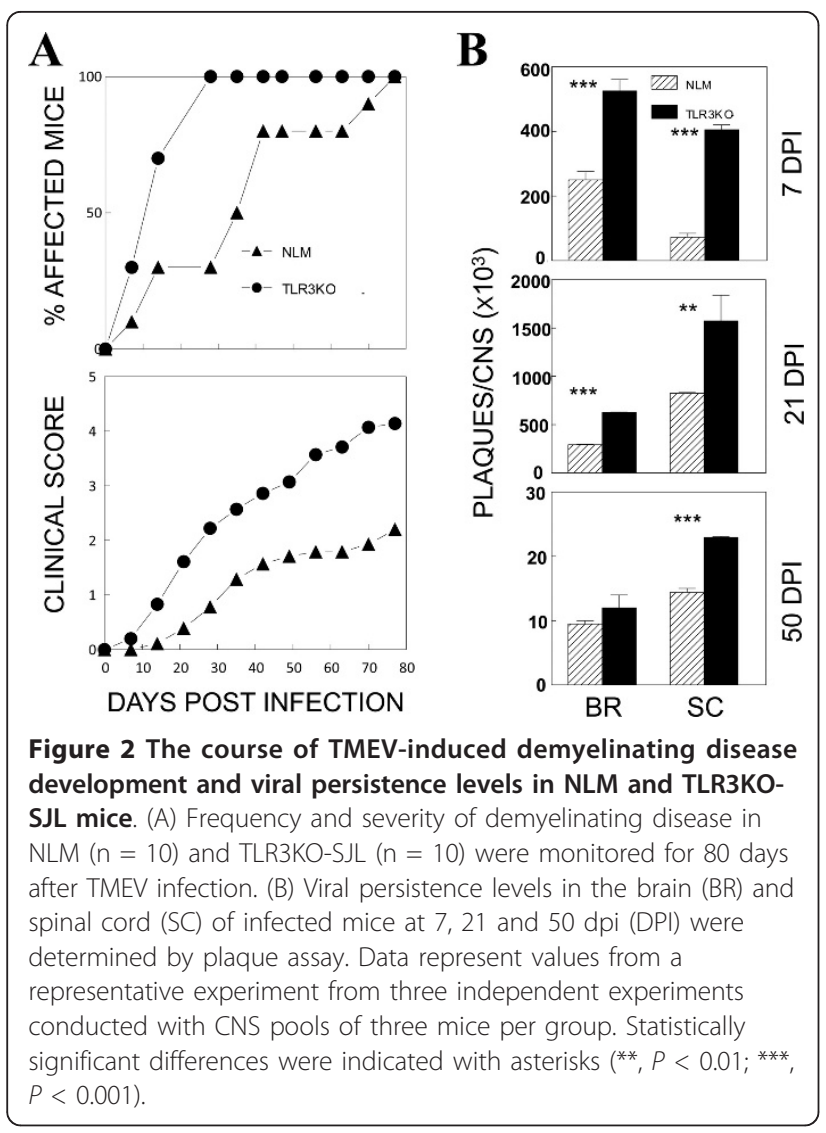

TLR3KO-SJL mice display severe demyelination and inflammation in the CNS

To compare levels of demyelination in the CNS of TMEV BeAn-infected TLR3KO-SJL and NLM SJL mice, histopathologic examinations were performed (Figure 3). First, Hematoxylin-eosin (HE) staining (Figure 3Aa and 3Ad), Kluver-Barrera's (KB) staining (Figure $3 \mathrm{Ab}$ and 3Ae) and immunohistochemical staining for GFAP (Figure 3Ac and 3Af) were conducted. In each experiment, mice from the NLM or TLR3KO groups were blindly selected, beforehand, for histological examination, and these mice were sacrificed at $27 \mathrm{dpi}$. The HE staining results showed that slight mononuclear cell infiltration (arrow) and mild demyelination were observed in the white matter of the spinal cord from NLM mice (Figure $3 \mathrm{Aa}$ and $3 \mathrm{Ab})$. GFAP staining showed a lack of astrocytes in the demyelinated lesion (arrow) (Figure 3Ac). In contrast, markedly increased mononuclear cell infiltration (arrow) and extended demyelination (arrow) were observed in the white matter of the spinal cord from TLR3KO mice (Figure 3Ad and 3Ae). GFAP staining showed markedly increased number of activated astrocytes in the white matter of the spinal cords of these mice (Figure 3Af).
Next, we examined the spinal cords of TMEV-infected NLM and TLR3KO-SJL mice at days 10 and 27 post infection using immunohistochemical staining for CD3, a marker of $\mathrm{T}$ cells (Figure $3 \mathrm{Ba}, 3 \mathrm{Bd}, 3 \mathrm{Bg}$, and $3 \mathrm{Bj}$ ); CD45R, a marker of $\mathrm{B}$ cell (Figure $3 \mathrm{Bb}, 3 \mathrm{Be}, 3 \mathrm{Bh}$, and $3 \mathrm{Bk}$ ); and F4/80, a marker of macrophages (Figure 3Bc, $3 \mathrm{Bf}, 3 \mathrm{Bi}$, and $3 \mathrm{Bl}$ ). Increased $\mathrm{T}$ cell infiltration was observed in the white matter of the spinal cord from TLR3KO mice (Figure 3Bd and 3Bj) compared to NLM mice (Figure $3 \mathrm{Ba}$ and $3 \mathrm{Bg}$ ), based on immunohistochemical staining for CD3. Few B cells were observed in the NLM (Figure $3 \mathrm{Bb}$ ) and the TLR3KO mice at day 10 post-infection (Figure 3Be). On day 27 post-infection, B cell infiltration was increased in the white matter of the spinal cord from TLR3KO mice (Figure 3Bk) compared to NLM mice (Figure 3Bh). Similarly, macrophage infiltration was determined by staining for the F4/80 marker, and higher levels of macrophages were found in the white matter of the spinal cord from TLR3KO mice (Figure $3 \mathrm{Bf}$ and $3 \mathrm{Bl}$ ) compared to NLM mice (Figure $3 \mathrm{Bc}$ and $3 \mathrm{Bi}$ ) at 10 and $27 \mathrm{dpi}$.

\section{Levels of cellular infiltration, viral load and type I IFN production are elevated in the CNS of TLR3-deficient mice}

To determine the levels of CNS-infiltrating mononuclear cells, we compared the mononuclear cells that accumulated in the CNS of NLM and TLR3K-SJL mice. The numbers of CNS-infiltrating mononuclear cells were elevated throughout the course of viral infection (days 7 , 21 and 80) in TLR3KO-SJL mice compared to NLM (Figure 4A). Flow cytometric analysis of the CNS infiltrating mononuclear cells indicated that the proportions of both the $\mathrm{CD}^{+}$and $\mathrm{CD}^{+} \mathrm{T}$ cells in TLR3KO-SJL mice were significantly higher than those of the NLM group at 7 and $21 \mathrm{dpi}$ (Figure 4B). The proportions of macrophages $\left(\mathrm{CD} 11 \mathrm{~b}^{+} \mathrm{CD} 45^{\text {high }}\right)$ and neutrophils (Ly6G/ $6 \mathrm{C}^{+}$) were also higher in TLR3KO-SJL mice compared to NLM.

To understand the underlying mechanisms of exacerbated susceptibility to TMEV-induced demyelinating disease in TLR3KO-SJL mice, we compared the expression levels of TMEV RNA and cytokine genes in the CNS of virus-infected NLM and TLR3KO-SJL mice at 7 and 21 dpi (Figure 4C). The viral message level was significantly elevated at both time points in TLR3KO-SJJL mice, consistent with the higher replicating virus levels determined using plaque assays (Figure 2B). The expression of various inflammatory cytokine genes, such as type I IFNs, IL-10, TNF- $\alpha$, IL-6, and IL-1 was similarly elevated in the CNS of TLR3KO-SJL mice. It was interesting to note that the expression of CXCL-10, associated with $\mathrm{T}$ cell infiltration to the CNS, was also highly elevated in TLR3KO-SJL mice. Because TLR3 is 

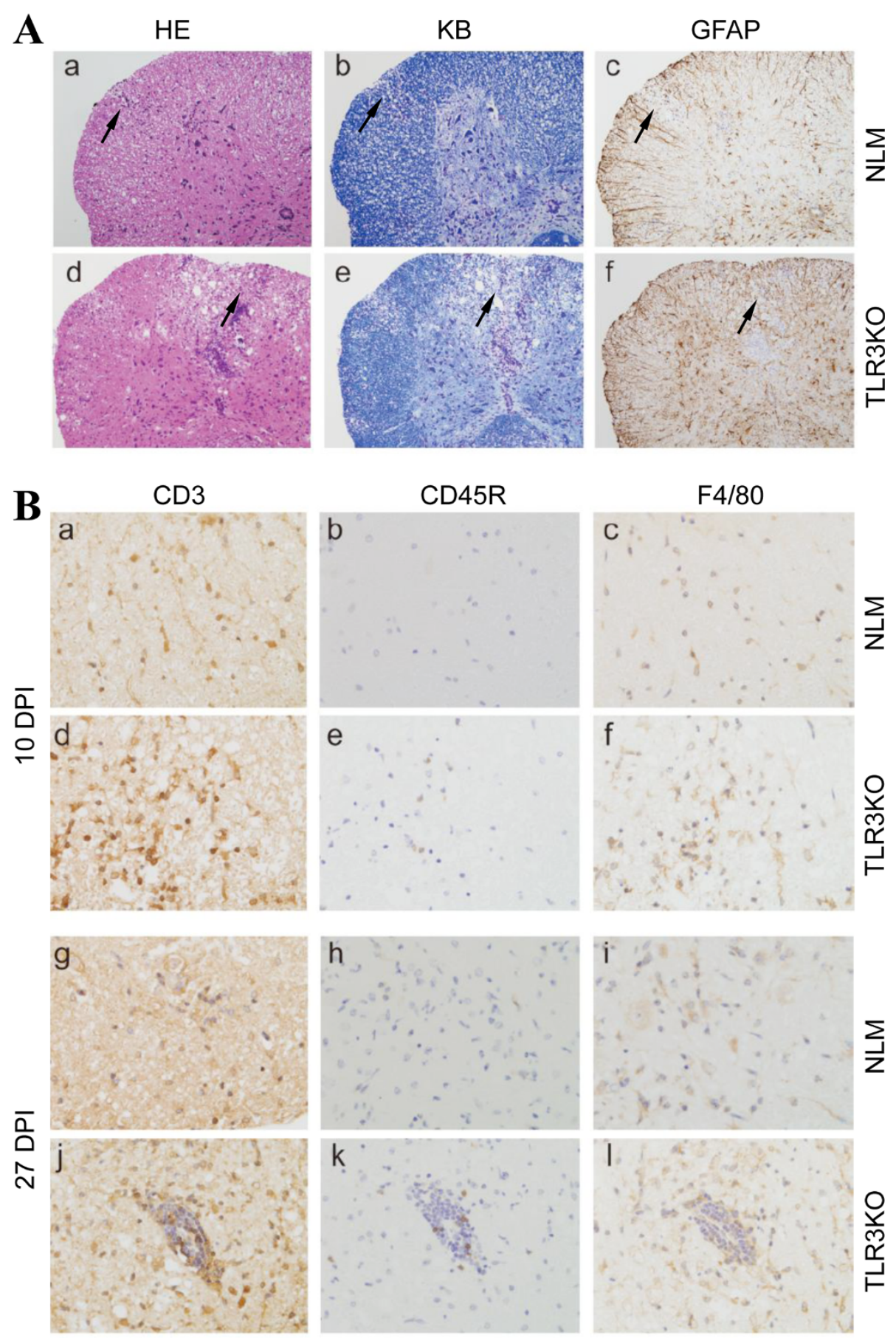

Figure 3 Histopathology of TMEV-infected NLM and TLR3KO-SJL mice. (A) Hematoxylin-eosin (HE) staining (a, d), Kluver-Barrera (KB) staining $(b, e)$ and immunohistochemical staining for GFAP, astrocyte marker $(c, f)$ of spinal cord from NLM or TLR3KO-SJL mice were done at 27 dpi (DPI). Original magnification, 100x. (B) Immunohistochemical staining for CD3 (a, d, g, and j), CD45R, a marker of B cell (b, e, h, and k), and F4/80, a marker of macrophage ( $\mathrm{C}, \mathrm{f}, \mathrm{i}$, and $\mathrm{I})$ of the spinal cord from NLM or TLR3KO-SJL mice were done at days 10 and 27 post infection. Original magnification, 400x. 


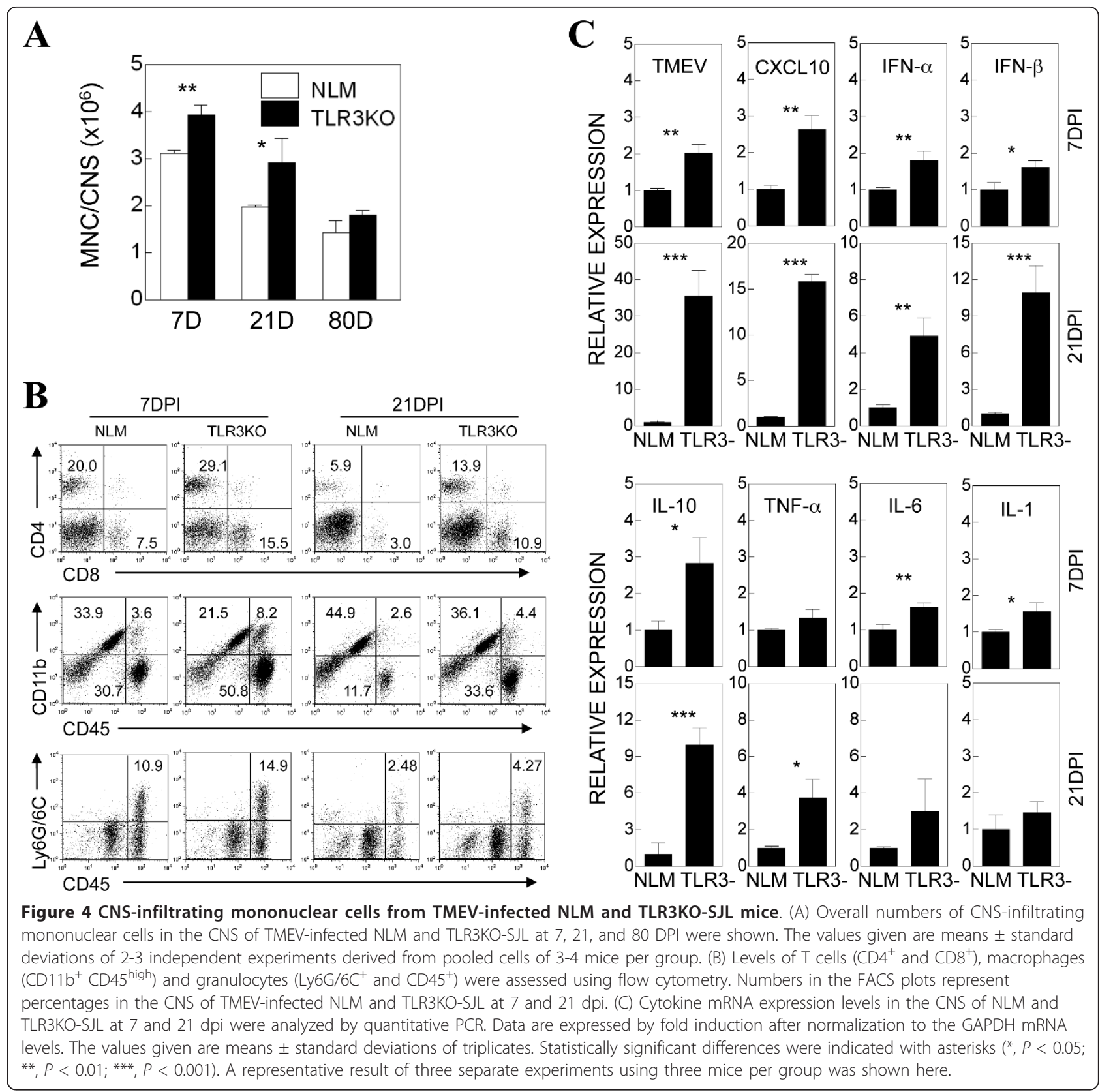

known to play an important role in activating the expression of these cytokine genes [16], an increased viral load in the absence of TLR3 signaling may be sufficient to overcome the TLR3 deficiency via other receptors, such as MDA5, leading to elevated cytokine gene expression. Consequently, higher viral loads accompanied by more proinflammatory cytokines may result in elevated cellular infiltration and exacerbated development of demyelinating disease in TLR3KO-SJL mice.
Late, but not early, anti-viral T cell responses are compromised in TLR3KO-SJL mice

To determine the levels of virus-specific $\mathrm{T}$ cell responses in the CNS, mononuclear cells isolated from the CNS of TMEV-infected NLM and TLR3KO-SJL mice at 7 and $21 \mathrm{dpi}$ were stimulated with viral epitope peptides and assayed for the production of IFN- $\gamma$ (Figure 5A-D). The proportion of TMEV-specific IFN- $\gamma$-producing $\mathrm{CD} 4^{+} \mathrm{T}$ cells and $\mathrm{CD}^{+} \mathrm{T}$ cells in the CNS of TLR3KO-SJL mice 


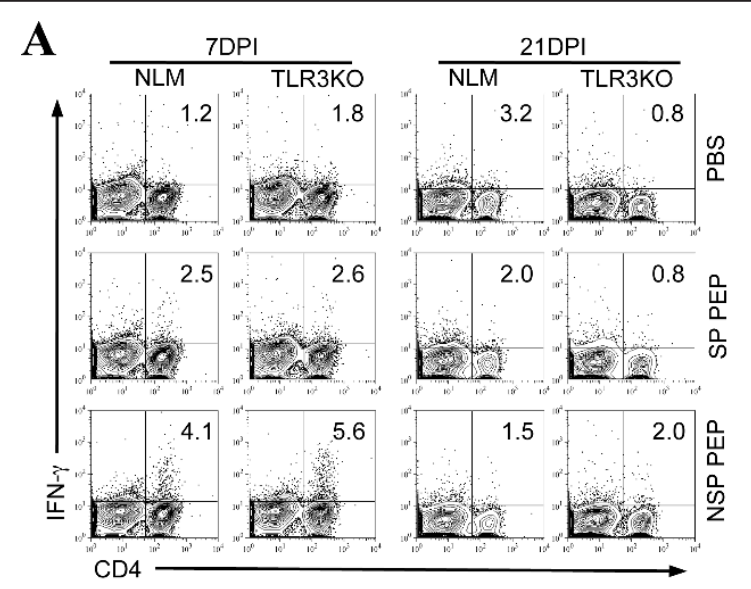

C

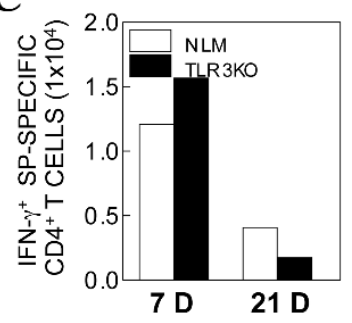

$\mathbf{E}$
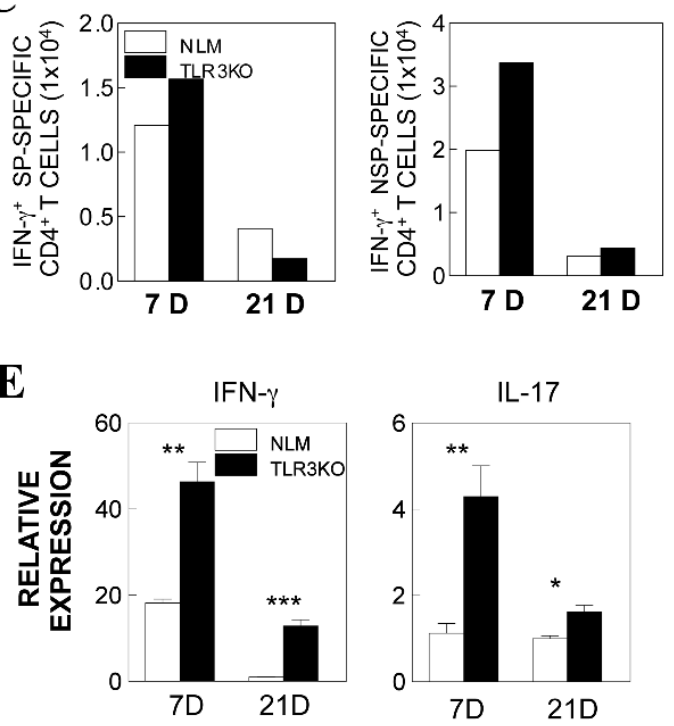

$\mathbf{F}$

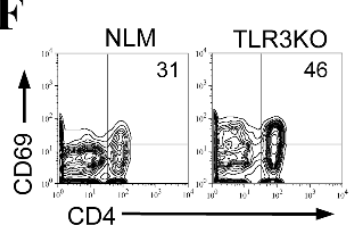

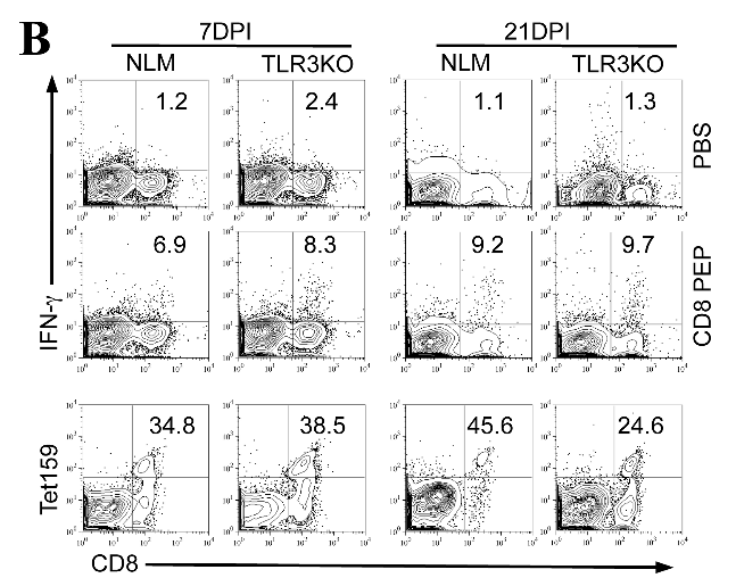

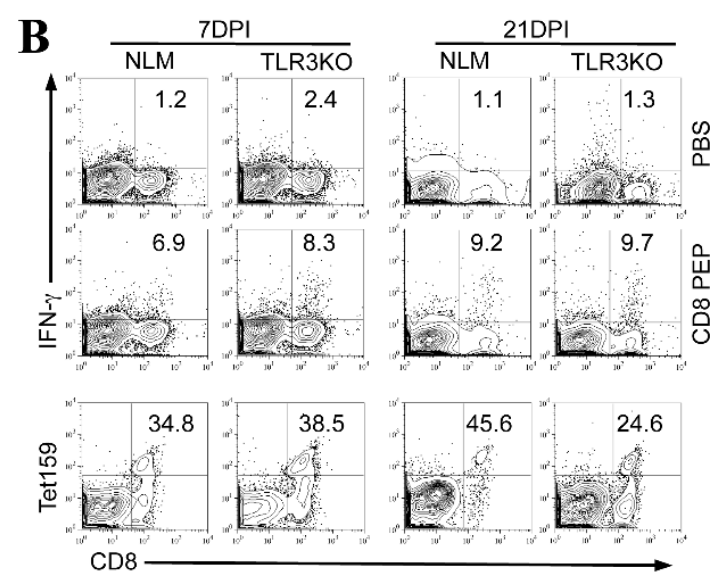

D

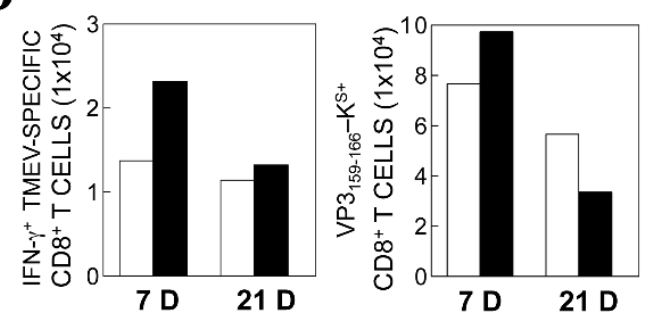

G $\frac{M G}{N L M \quad T L R 3 K O}$
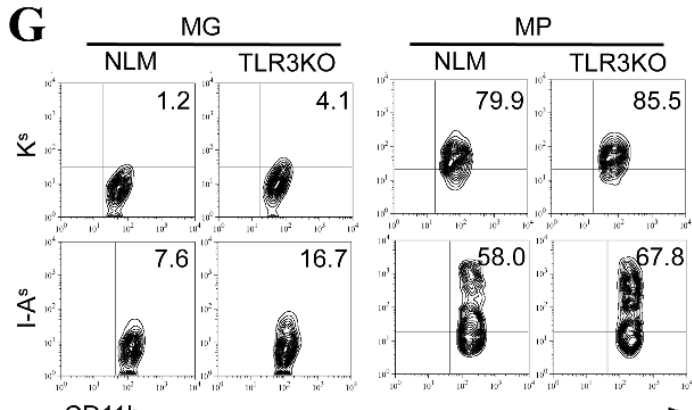

CD11b

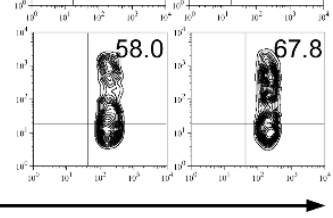

Figure $5 \mathrm{CD}^{+}$and $\mathrm{CD}^{+}{ }^{+}$cell responses to viral epitopes in TMEV-infected NLM and TLR3KO-SJL mice. (A) Proportions of IFN- $\gamma-$ producing $\mathrm{CD}^{+}$cells in the CNS were determined by intracellular staining after stimulation with $2 \mu \mathrm{M}$ of SJL CD4 capsid (SJL SP) or SJL CD4 noncapsid (SJL NSP) epitope mixtures. Numbers in the FACS plots represent \% of IFN- $\gamma$ producing CD4 ${ }^{+}$cells from total infiltrating CD4 ${ }^{+}$cells. (C) IFN- $\gamma$-producing CD4 $4^{+}$cell numbers in the CNS at 7 and 21 dpi were shown after stimulation with SJL CD4 capsid (SJL SP) (left panel) or SJL CD4 noncapsid (SJL NSP) (right panel) epitope mixtures. (B) Proportions of IFN- $\gamma$-producing CD8 ${ }^{+}$cells in the CNS were determined by intracellular staining after stimulation with $2 \mu \mathrm{M}$ of SJL CD8 epitope mixture. Numbers in the FACS plots represent \% of IFN- $\gamma$ producing CD8 ${ }^{+}$ cells from total infiltrating $\mathrm{CD} 8^{+}$cells. Numbers in the bottom panel represent $\%$ of $\mathrm{H}-2 \mathrm{~K}^{5}-\mathrm{VP} 3_{159-166}$ tetramer-positive CD8 ${ }^{+}$cells from total infiltrating $\mathrm{CD}^{+}$cells without further stimulation. (D) IFN- $\gamma$-producing $C D 8^{+}$cell numbers after stimulation with SJL CD8 epitopes (left panel) and total numbers of $\mathrm{H}-2 \mathrm{~K}^{5}-\mathrm{VP} 3_{159-166}$ tetramer-reactive $\mathrm{CD} 8^{+}$cells in the CNS at 7 and 21 dpi were shown (right panel). (E) The relative expression levels of IFN- $\gamma$ vs. IL-17 mRNAs in the CNS of virus-infected TLR3KO-SJL and NLM were assessed by real-time PCR. Data are expressed by fold induction after normalization to the GAPDH mRNA levels. The values given are means \pm standard deviations of triplicates. Statistically significant differences were indicated with asterisks ( ${ }^{*}, P<0.05$; $\left.{ }^{*}, P<0.01 ; * * *, P<0.001\right)$. (F) Expression of CD69, activation marker of CD4 and CD8 from TMEV-infected NLM and TLR3KO-SJ mice at 7 DPI was analyzed by FACS. Numbers in cytometric plots represent $\%$ of positive CD4 $4^{+}$or CD $8^{+} T$ cells out of the total $\mathrm{CD}^{+}$or $\mathrm{CD} 8^{+} \mathrm{T}$ cells, respectively. (G) Expression levels of $\mathrm{MHC}$ class I $\left(\mathrm{H}-2 \mathrm{~K}^{5}\right)$ and II (I-A $\mathrm{A}^{5}$ ) molecules on microglia (MG) and macrophages (MP) of TMEV-infected NLM and TLR3KO-SJL mice were analyzed at 7 dpi by flow cytometry. Numbers in cytometric plots represent \% of positive MG or MP out of the total MG or MP, respectively. 
were consistently similar or higher than those of the NLM mice at 7 dpi. The proportion of $\mathrm{H}-2 \mathrm{~K}^{\mathrm{s}}-\mathrm{VP} 3_{159}$ 166-tetramer reactive $\mathrm{CD}^{+} \mathrm{T}$ cells in the CNS of TLR3KO mice was also similar to that of the NLM mice at the early stage $(7 \mathrm{dpi})$ of infection, indicating the similarities in the function of virus-specific $\mathrm{CD} 8^{+} \mathrm{T}$ cells in both mouse groups. However, the overall numbers of virus-specific $\mathrm{CD}_{4}^{+}$and $\mathrm{CD} 8^{+} \mathrm{T}$ cells in the CNS were higher due to the increased cellular infiltration to the CNS in TLR3KO-SJL mice. The proportion and number of anti-viral $\mathrm{CD}^{+}{ }^{+} \mathrm{T}$ cells became similar or lower in

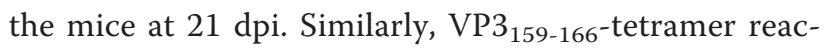
tive $\mathrm{CD}^{+} \mathrm{T}$ cells were lower at $21 \mathrm{dpi}$ in the TLR3KOSJL mice, although IFN- $\gamma$-producing $\mathrm{CD}^{+} \mathrm{T}$ cells remained similar. It has previously been shown that Th17 cells are preferentially developed following TMEV infection and IL-17 promotes the pathogenesis of chronic demyelinating disease [35]. To further determine the levels of IL-17-producing $\mathrm{T}$ cells relative to IFN- $\gamma$-producing cells in the virus-infected mice, the overall levels of IFN- $\gamma$ and IL-17 messages expressed in the CNS were assessed using real-time PCR (Figure 5E). The results confirmed the higher level of IFN- $\gamma$-producing cells observed by flow cytometry in virus-infected TLR3KO-SJL mice. In addition, the level of IL-17-producing $\mathrm{T}$ cells was similarly higher in TLR3KO mice compared to the control littermates. These results suggest that antiviral $\mathrm{T}$ cell responses are not drastically altered but rather, are elevated in TMEV-infected SJL mice in the absence of TLR3 signals.

To further examine the status of $\mathrm{T}$ cell activation in TLR3KO-SJL mice during early viral infection, the expression of the CD69 activation marker on T cells and MHC molecules on microglia and macrophages in the CNS of virus-infected mice were analyzed at $7 \mathrm{dpi}$ by flow cytometry (Figure 5F and 5G). Levels of CD69 expression on $\mathrm{CD} 4^{+}$and $\mathrm{CD} 8^{+} \mathrm{T}$ cells were higher in the TLR3KO-SJL mice compared to NLM mice, consistent with the higher proportions of virus-specific $\mathrm{T}$ cells (Figure 5A and 5B). The expression levels of both MHC class I $\left(\mathrm{H}-2 \mathrm{~K}^{\mathrm{s}}\right)$ and II $\left(\mathrm{I}-\mathrm{A}^{\mathrm{s}}\right)$ molecules were also higher on microglia (MG) and macrophages (MP) from TMEV-infected TLR3KO mice (Figure 5G). These results suggest that early efficient $\mathrm{T}$ cell activation, in the absence of TLR3 signaling, may be due to the elevated expression of MHC molecules on antigen presenting cells.

\section{Treatment of SJL mice with poly IC prior to viral infection, not after infection, exacerbates disease development, accompanied with elevated cellular infiltration to the CNS}

To activate TLR3 signaling, susceptible SJL mice were intraperitoneally treated with poly IC, the representative
TLR3 ligand, at 1 day prior to or 8 days post TMEVinfection. The progression of TMEV-induced demyelinating disease was assessed over $63 \mathrm{dpi}$. Mice treated with poly IC at 1 day prior to viral infection displayed an exacerbated development of disease, whereas mice treated with poly IC at 8 dpi resulted in a slower onset of the disease compared to virus-infected SJL mice without poly IC administration (Figure 6A). Viral message levels in the brain and spinal cord of mice pretreated with poly IC were significantly higher than those of the mice that were either untreated or treated with poly IC at $8 \mathrm{dpi}$ (Figure 6B). These results indicate that the activation of TLR3 prior to viral infection leads to an increased viral load in the CNS and accelerated pathogenesis of demyelinating disease; however, such activation after viral infection does not alter the development of disease.

To further understand the immunological mechanisms of the acceleration of TMEV-induced demyelinating disease in poly IC-pretreated SJL mice, we first compared the levels of mononuclear cells accumulated in the CNS of mice at 14 and 28 dpi (Figure 6C and 6D). Flow cytometric analysis showed that the proportion of macrophages $\left(\mathrm{CD} 11 \mathrm{~b}^{+} \mathrm{CD} 45^{\text {high }}\right)$ in the CNS of poly IC pretreatment mice was elevated, whereas the proportion in the CNS of poly IC post-treated mice remained the same as that of virus-infected mice without poly IC treatment (Figure 6C). It is interesting to note that poly IC-pretreated mice maintained the elevated macrophage level at $28 \mathrm{dpi}$, while in poly IC-post-treated mice the level decreased. Similarly, the proportion of $\mathrm{CD} 4^{+}$and $\mathrm{CD}^{+}$cells was higher in the CNS of the poly IC pretreatment mice and remained higher at $28 \mathrm{dpi}$ compared to the untreated virus-infected mice. However, the proportion of these $\mathrm{T}$ cells in the CNS of poly IC-post-treated mice was lower (Figure 6D), and these decreases appear to reflect decreased levels of viral message in the CNS (Figure 6B).

To further assess the relative levels of virus-specific $\mathrm{T}$ cell responses in the CNS of these poly IC treated mice, mononuclear cells isolated from the CNS of infected mice at 14 and 28 dpi were stimulated with viral epitope peptides to determine the ability of these cells to produce IFN- $\gamma$. The flow cytometry profiles of the mononuclear cells at day 28 post-infection are shown in Figure 6 (panels $\mathrm{E}$ and F). The proportions of both IFN$\gamma$-producing virus-specific $\mathrm{CD} 4^{+}$and $\mathrm{CD}^{+} \mathrm{T}$ cells in the CNS of poly IC pre-treated mice were markedly decreased at both time points (results at day 14 postinfection not shown) compared to those of the control mice without poly IC-treatment. In contrast, the proportion of $\mathrm{CD} 4^{+}$and $\mathrm{CD}^{+} \mathrm{T}$ cells in the poly IC-post-treated mice were increased particularly around the onset of disease development ( $28 \mathrm{dpi})$. These results strongly 
A

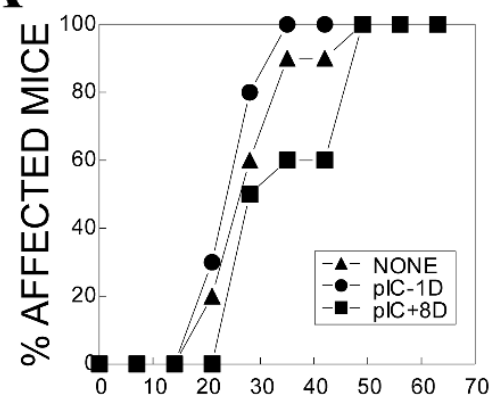

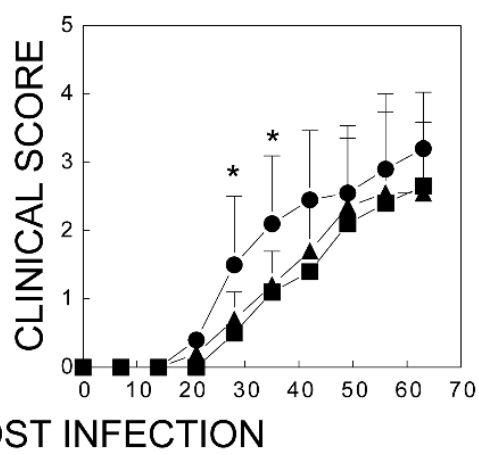

B

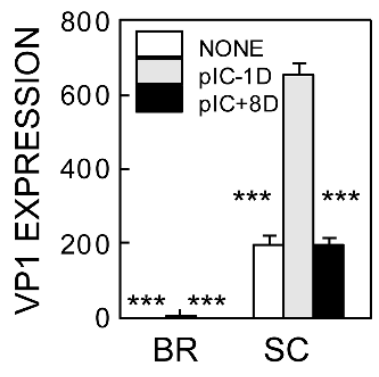

C

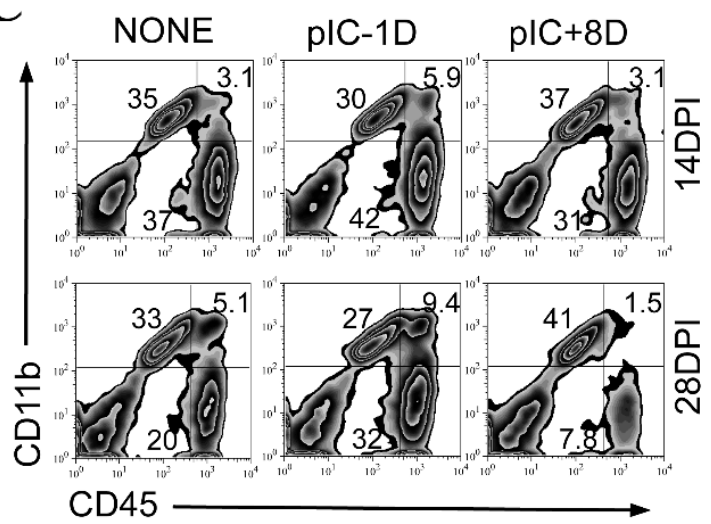

$\mathbf{E}$

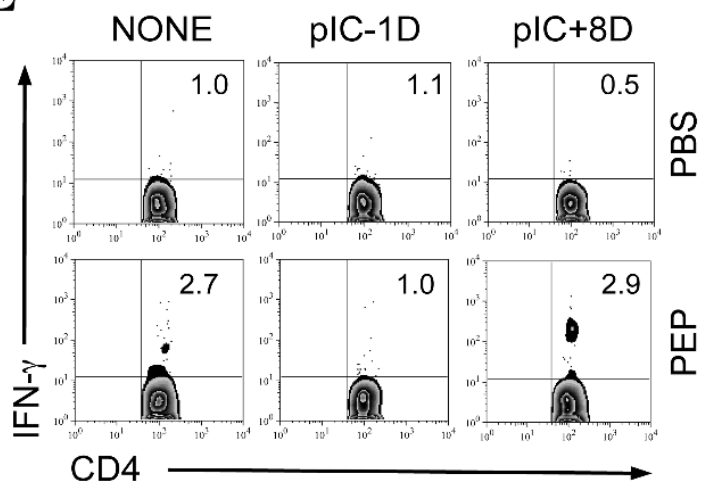

D

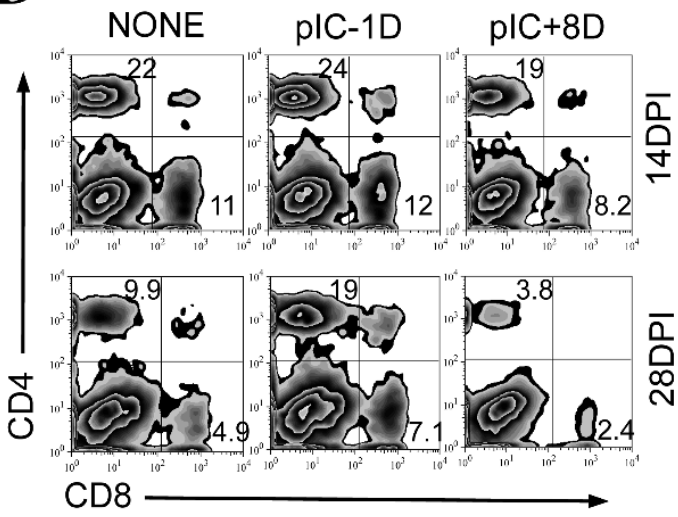

$\mathbf{F}$

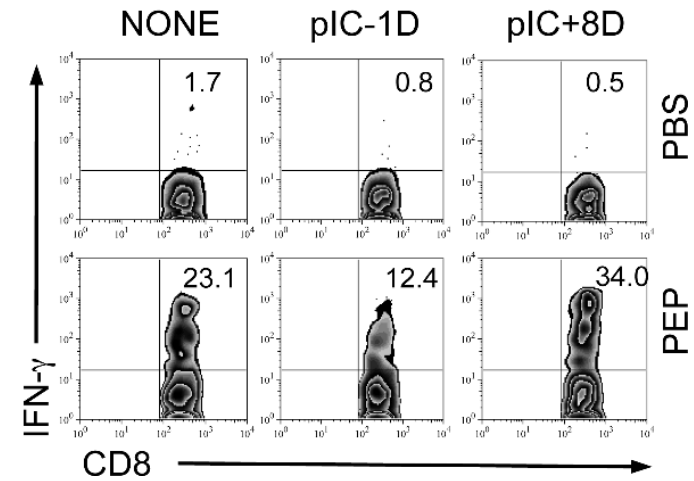

Figure 6 Administration of poly IC at 1 day prior to or $\mathbf{8}$ days post TMEV infection into SJL mice. Mice were intraperitoneally injected with either PBS or $50 \mu \mathrm{g}$ of poly IC (Sigma) in $100 \mu \mathrm{l}$ at day -1 or +8 relative to viral infection. (A) Frequency and severity of demyelinating disease in SJL mice after ip injection with poly IC at 1 day prior to $(n=10)$ or 8 days post $(n=10)$ TMEV infection were monitored for 63 days after TMEV infection. Statistically significant differences in Student's t-test were indicated with asterisks $\left({ }^{*}, P<0.05\right)$. Paired t-tests (two-tailed) between 20-63 dpi indicated that the difference between untreated and pretreated groups was very significant $(P<0.0026)$ and the difference between untreated and post-treated groups was significant $(P<0.0189)$. (B) Viral persistence levels in the brain (BR) and spinal cord (SC) of infected mice at $14 \mathrm{dpi}$ were determined using quantitative PCR. Data are expressed by fold induction after normalization to the GAPDH mRNA levels. The values given are means \pm standard deviations of triplicates. Statistically significant differences were indicated with asterisks $\left({ }^{*}, P<0.05\right.$; ${ }^{* *}, P<0.01$; ${ }^{* *}, P<0.001$ ). (C and D) CNS-infiltrating mononuclear cells from SJL mice with treatment of poly IC at -1 day or +8 days post TMEV infection were shown. Numbers in FACS plots represent percentages in the total CNS-infiltrating cells. Data are representative of three experiments using three mice per group. (E) Levels of IFN- $\gamma$ producing $C D 4^{+}$cells in the CNS were determined by intracellular staining after stimulation for 6 hours with $2 \mu \mathrm{M}$ CD4 epitope peptides at 28 dpi. (F) Levels of IFN- $\gamma$ producing CD $8^{+}$cells in the CNS were determined by intracellular staining after stimulation for 6 hours with $2 \mu \mathrm{M}$ CD8 viral epitope peptides at 28 dpi. Numbers in the FACS plots represent percentages in total CD4 or CD8 cells. Data are representative of three experiments using three mice per group. 
suggest that activation of TLR3 signaling prior to viral infection hinders the induction of protective IFN- $\gamma$-producing $\mathrm{CD}^{+}$as well as $\mathrm{CD} 8^{+} \mathrm{T}$ cell populations. In contrast, activation of these signals after viral infection appears to improve the induction of IFN- $\gamma$-producing $\mathrm{CD}^{+}{ }^{+}$as well as $\mathrm{CD} 8^{+} \mathrm{T}$ cells.

\section{Expression of antigen presentation-associated molecules is elevated in CNS CD11 b $\mathrm{b}^{+}$cells in poly IC-pretreated mice but reduced in post-treated mice}

To further determine whether the decrease of IFN- $\gamma$ producing $\mathrm{T}$ cells in poly IC-pretreated mice (Figure $6 \mathrm{E}$ and $6 \mathrm{~F}$ ) reflects the inability of antigen presenting cells to stimulate $\mathrm{T}$ cell responses in the CNS of poly IC preor post-treated SJL mice, expression levels of CD69, an activation marker of $\mathrm{CD}^{+}$and $\mathrm{CD}^{+}$cells, were compared at 14 and 28 dpi (Figure 7A). Overall, the expression levels of $\mathrm{CD} 69$ on $\mathrm{CD}^{+}$and $\mathrm{CD} 8^{+}$cells were similar among the untreated control and the poly IC pre- and post-treated mice at both 14 and $28 \mathrm{dpi}$, although the expression of $\mathrm{CD} 69$ on $\mathrm{CD} 8^{+} \mathrm{T}$ cells of poly IC-post-treated mice was somewhat lower. These data suggest that the decrease in IFN- $\gamma$-producing $\mathrm{T}$ cell responses in poly IC-pretreated mice does not reflect the status of T cell activation in the CNS.

To verify the status of antigen presenting cells in the $\mathrm{CNS}$, we examined the expression levels of MHC classes I and II, and CD40 molecules, which are associated with $\mathrm{T}$ cell activation, on the major antigen-presenting $\mathrm{CD}_{11} \mathrm{~b}^{+}$cells, including microglia and macrophages (Figure 7B and 7C). The expression levels of MHC class $\mathrm{I}\left(\mathrm{H}-2 \mathrm{~K}^{\mathrm{s}}\right)$ and II $\left(\mathrm{I}-\mathrm{A}^{\mathrm{s}}\right)$ molecules on $\mathrm{CD}_{11} \mathrm{~b}^{+}$cells in the poly IC pretreated mice were markedly increased, whereas the levels in the poly IC post-treated mice were decreased compared to those in the untreated control virus-infected mice. These data suggested that the poor IFN- $\gamma$-producing $\mathrm{T}$ cell responses were not due to a deficiency in the expression of molecules associated with antigen presentation. It was also interesting to note that the levels of both $\mathrm{T}$ cell activation and expression of MHC and CD40 molecules appeared to correlate with viral load in the CNS.

To further explore possible mechanisms underlying the poor IFN- $\gamma$-producing $\mathrm{T}$ cell responses in poly ICpretreated mice, we assessed the expression levels of PDL-1, an inhibitory molecule for both $\mathrm{CD}_{4}^{+}$and $\mathrm{CD} 8^{+}$ $\mathrm{T}$ cell responses [36], on $\mathrm{CD}_{11 \mathrm{~b}^{+}}$cells in the CNS (Figure 7D). We chose PDL-1 as a candidate inhibitory molecule because this molecule is known to play a critical role in anti-viral $\mathrm{T}$ cell functions in virus-infected hosts, and the expression of PDL-1 is inducible by activation of TLR3 with poly IC treatment $[36,37]$. The expression levels of PDL-1 on $\mathrm{CD}_{11 \mathrm{~b}^{+}}$cells were drastically increased in the poly IC pretreated mice at both 14 and $28 \mathrm{dpi}$, whereas the expression was markedly decreased in post-treated mice compared to those of TMEV-infected control mice without poly IC treatment. These results strongly suggest that the compromise in the immune response of mice treated with poly IC prior to virus infection was due in part to the over-expression of the inhibitory PDL-1 molecule on antigen presenting cells rather than deficiencies in the activation of $\mathrm{T}$ cells.

It is possible that the poor immune responses in the poly IC-pretreated mice may also have been associated with the induction of a higher level of regulatory FoxP3 ${ }^{+} \mathrm{CD}^{+}{ }^{+} \mathrm{T}$ cells (Treg), which are known to inhibit the function of anti-viral $\mathrm{T}$ cell responses [38-42]. To examine this possibility, levels of Foxp3 expressing CD4 ${ }^{+} \mathrm{T}$ cells in the CNS of control mice and mice treated with poly IC were assessed at 14 and $28 \mathrm{dpi}$ (Figure 7E). The level of Treg cells in the CNS of poly IC-pretreatment mice was significantly higher, particularly at the preclinical stage (14 dpi) compared to that of untreated control mice. In contrast, the Treg levels in mice treated with poly IC following viral infection were similar to the untreated control mice. These results suggest that an elevated induction of Fox $3^{+}$Treg cells may also partially contribute to the low $\mathrm{T}$ cell response in poly $\mathrm{IC}$ pretreated mice.

\section{Discussion}

We have previously demonstrated that cells infected with TMEV stimulate the innate inflammatory response mainly via TLR3-mediated signaling $[16,17]$. However, the role of TMEV-induced TLR3 signaling in protection from and/or pathogenesis of demyelinating disease remains unknown. In this study, we examined the potential role of TLR3 in the progression of TMEVinduced demyelinating disease by utilizing TLR3 KO mice and administering TLR3 ligand. Our results demonstrate that TLR3-mediated signals do not play a major role in the protection of mice in the resistant C57BL/6 background against BeAn, a less virulent strain of TMEV. However, TLR3 stimulation plays a protective role in infection with GDVII, a neurovirulent TMEV strain (Figure 1). These results are consistent with previous studies demonstrating that the absence of TLR3 in B6 mice does not alter the adaptive immune response or viral pathogenesis of chronic viral infections [10]. In contrast, it has also been reported that the presence of TLR3 provides protection from acute viral infections with West Nile virus [6] and Coxsackievirus B4 [7]. Therefore, it appears that TLR3 may provide some protection against acute or virulent viral infections but not against non-virulent viral infections.

In contrast to resistant C57BL/6 mice, SJL mice are susceptible to persistent chronic infection in the CNS with the less virulent BeAn strain of TMEV, and the 


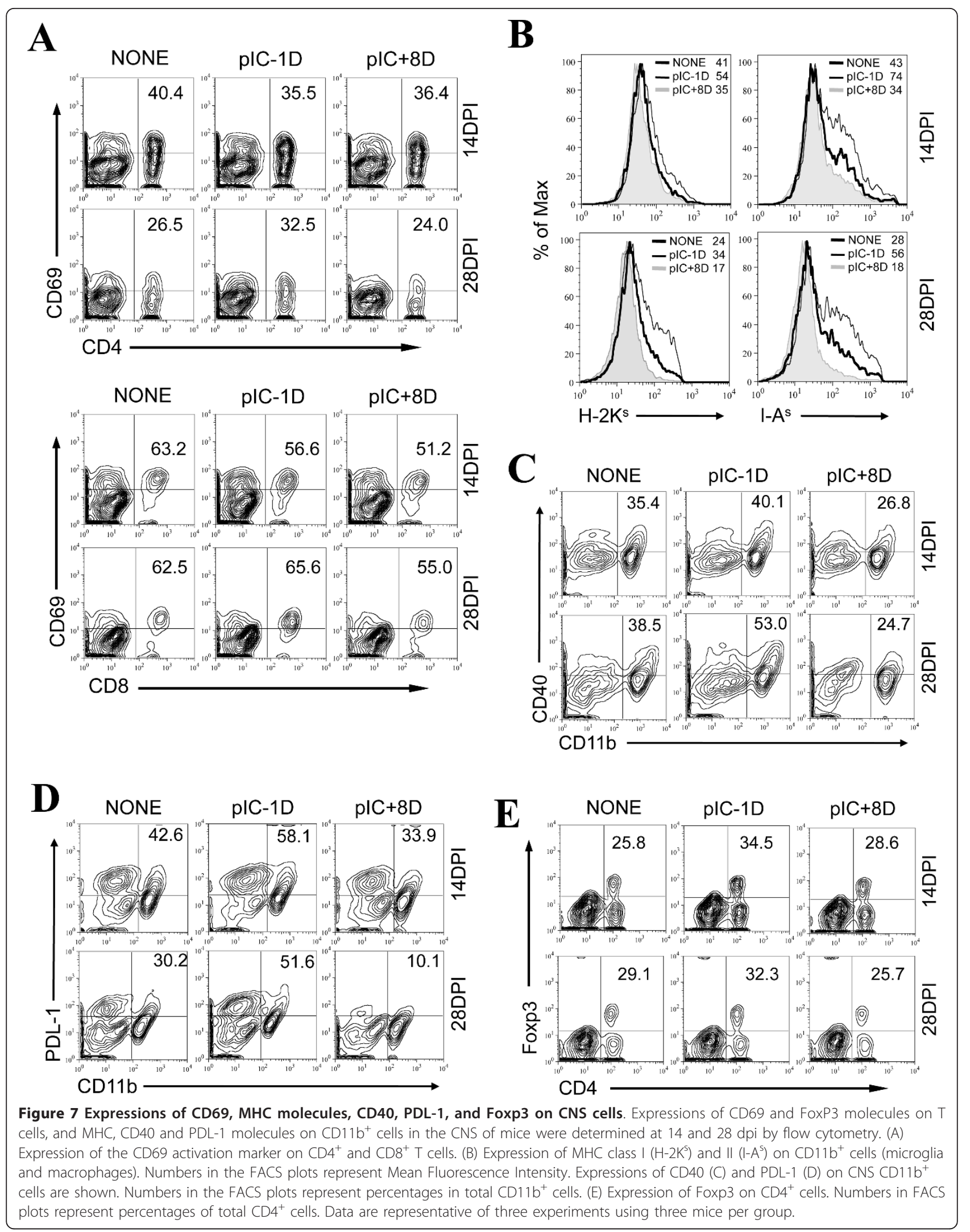


majority of infected mice develop demyelinating disease starting from 20-35 dpi [15]. Our current results indicate that the presence of TLR3-mediated signals provides protection from the development of TMEVinduced demyelinating disease in susceptible SJL mice, as TLR3-deficient mice with the SJL background genes showed elevated viral loads in the CNS and exacerbated disease development (Figures 2 and 3). Therefore, TLR3-mediated protection may play an important role in the susceptible host that only mounts a marginal protective response against chronic viral infections. While the early adaptive immune response to viral infections was not altered in the absence of TLR3-mediated signals (Figure 5), consistent with a previous report [10], cellular infiltration into the CNS was markedly elevated (Figure $4 \mathrm{~A}$ and $4 \mathrm{~B}$ ), resulting in exacerbation of TMEVinduced immune-mediated demyelinating disease (Figure $2 \mathrm{~A}$ ). The increased cellular infiltration may be due to high viral loads in the absence of TLR3 signals (Figure $2 \mathrm{~B}$ ), which leads to high levels of proinflammatory cytokine production in the CNS, thus facilitating cellular infiltration (Figure 4C). However, the elevated cytokine production in the CNS of virus-infected TLR3KO mice was unexpected, as TLR3 is essential for the production of cytokines, such as type I IFNs and IL-6, in TMEV infected glial cells $[16,17]$. Therefore, these results strongly suggest that high viral loads in the CNS led to the utilization of an alternative innate immunity pathway, such as MDA5 and/or PKR, which stimulate proinflammatory cytokine production, as previously described $[4,24,43,44]$. Since cells from TLR3KO mice can also produce cytokines upon stimulation with poly IC, these alternative signal-triggering molecules appear to be operational in these mice (not shown). Nevertheless, TLR3-mediated signals appear to provide a protective function, particularly in hosts susceptible to virusinduced disease.

It is interesting to note that there is a disconnect between the levels of type I IFNs and control of TMEV infection, hence TRLR3KO mice display higher levels of type I IFNs yet more susceptible to TMEV infection (Figures 2 and 4). These results are inconsistent with the previous studies with IFNIR-KO mice, which displayed fatal encephalitis upon TMEV infection [26,45]. Therefore, the presence of a certain level of type I IFN signaling during early TMEV infection appears to be necessary for survival of the animals. The high level of type I IFN production in TLR3KO mice is likely activated via primarily MDA5 signaling by a high viral load, because an MDA5-mediated signal is the major activator for type I IFN production in mice following infection with TMEV $[24,46]$. However, high levels of type I IFNs may not be necessarily helpful in controlling viral infection. In fact, both IFN- $\alpha$ and IFN- $\beta$ levels were significantly higher in mice pretreated with poly IC compared to either untreated or treated at 8 dpi (Additional file 2, Figure S2). Furthermore, our previous results indicated that susceptible SJL mice produce higher levels of type I IFNs compared to resistant B6 mice and a high level of IFNs exacerbates viral infection by inhibiting induction of protective immune responses [21]. Therefore, the exceeding levels of type I IFNs appear to play a detrimental role in the protection from virus-induced chronic demyelinating disease.

Interestingly, premature activation of TLR3 via administration of poly IC prior to viral infection promoted disease progression. In contrast, additional TLR3 signals by poly IC after viral infection yielded a clinical improvement and less pathogenic immune responses in the CNS (Figure 6). These results suggest that TLR3 signaling provides differential protection against viral infection, depending on the time of the signals with respect to viral infection. It was previously shown that the presence of external poly IC mainly stimulates TLR3mediated signals for the production of various proinflammatory cytokines in many different cell types, including macrophages, microglia, and astrocytes $[3,16,19]$. Poly IC, a TLR3 ligand, has previously been used to protect the host from acute viral infections. Administration of poly IC between $<72$ hours prior to infection and $<24$ post infection with foot and mouth disease virus protected mice from death [47]. Similarly, poly IC treatment at 1 day prior to infection through 4 hours post virus challenge effectively prolonged the survival of mice from herpes simplex virus 2 challenges [28]. Therefore, the efficacy of TLR3-mediated protection from acute viral infection appears to be limited to a narrow time window. Furthermore, such poly IC treatment prior to viral infection may exacerbate the development of chronic virus-infection induced immunemediated diseases, such as TMEV-induced demyelinating disease (Figure 6). Interestingly, it has recently been shown that poly IC treatment enhances autoimmune disease in a retinal autoimmunity model [32]. Therefore, it is conceivable that the exacerbation of virus-induced disease by pretreatment with poly IC may not be limited to the development of chronic viral infection-induced immune mediated disease.

In contrast to the treatment with poly IC prior to viral infection, poly IC administration at 8 days after TMEV infection ameliorated disease development (Figure 6A). Recently, it has been shown that poly IC treatment of mice at 4 and 8 days after infection with Friend retrovirus reduces viral loads and promotes protection from the development of chronic viral infection-induced leukemia over a period of several weeks [29]. Therefore, TLR3-mediated signaling during chronic viral infection, particularly infections leading to immune-mediated 
diseases, appears to be protective, whereas premature activation of the signals prior to and/or at the time of viral infection may exacerbate the pathogenesis.

Our further analyses of the immune response in poly IC treated mice showed marked reductions in protective, virus-specific IFN- $\gamma$-producing $\mathrm{CD}_{4}^{+}$and $\mathrm{CD} 8^{+} \mathrm{T}$ cell responses in poly IC pretreated mice, in contrast to increases in poly IC post-treated mice (Figure 6E and 6 F). Furthermore, poly IC-pretreated mice displayed elevated expression of a $\mathrm{T}$ cell inhibitor, PDL-1, and an increased generation of regulatory FoxP $3^{+} \mathrm{CD}^{+} \mathrm{T}$ cells in the CNS, while poly IC-post-treated mice expressed reduced levels of PDL- 1 and FoxP $3^{+} \mathrm{CD}^{+} \mathrm{T}$ cells (Figure 7). The engagement of PD- $1 / 2$ or CD 80 with PDL- 1 exerts a powerful inhibitory function for $\mathrm{CD}^{+}$as well as $\mathrm{CD}^{+} \mathrm{T}$ cells in many virus systems (13). In addition, poly IC treatment is also known to upregulate PDL-1 expression [36,37]. Furthermore, it is interesting to note that poly IC-pretreated mice uniquely showed an increased level of $\mathrm{FoxP}^{+}$regulatory $\mathrm{CD}^{+} \mathrm{T}$ cells in the CNS of virus-infected mice. Although the underlying mechanisms for the increase are unknown, elevated levels of cytokines in the CNS of mice with high viral loads favoring the generation of FoxP $3^{+} \mathrm{CD} 4^{+} \mathrm{T}$ cells may contribute to the increase of the regulatory $\mathrm{T}$ cells. Nevertheless, FoxP3 ${ }^{+} \mathrm{CD}^{+}{ }^{+} \mathrm{T}$ cells generated in virusinfected hosts, including TMEV-infected mice, inhibit virus-specific $\mathrm{CD}^{+}$as well as $\mathrm{CD} 8^{+} \mathrm{T}$ cell function $[42,48]$. Therefore, these results strongly suggest that the activation of TLR3 signaling prior to virus infection may induce premature stimulation of regulatory immune mechanisms, hindering anti-viral immune cell function and leading to viral persistence. On the other hand, further activation of TLR3 signaling after viral infection appears to enhance anti-viral $\mathrm{T}$ cell function by reducing the expression of inhibitory PDL-1 and preventing the generation of regulatory $\mathrm{T}$ cells. These observations are particularly important, as the results imply that TLR-mediated stimulation of innate immunity as an intervention strategy for the treatment of viral infections could exacerbate the development of chronic immunemediated disease. Therefore, the timing of innate immunity stimulation should be carefully considered.

\section{Conclusions}

We reported previously that TLR3-mediated signaling is important in the induction of innate cytokine responses to TMEV infection. In this study, we investigated the role of TLR3-mediated signaling in the development of TMEV-induced demyelinating disease. TLR3KO mice in the susceptible SJL background displayed increased cellular infiltration and viral loads in the CNS, accompanied by exacerbated development of demyelinating disease. Activation of TLR3 with poly IC prior to viral infection also exacerbated disease development, whereas such activation after viral infection slowed disease development. An increased viral load in the absence of TLR3 signaling led to elevated cytokine production, cellular infiltration, and exacerbated development of demyelinating disease. Activation of TLR3 signaling prior to viral infection hindered the induction of protective IFN- $\gamma$ producing $\mathrm{CD} 4^{+}$and $\mathrm{CD} 8^{+} \mathrm{T}$ cell populations, but elevated PDL- 1 expression and regulatory $\mathrm{CD} 4^{+} \mathrm{T}$ cell generation in the CNS. These results suggest that TLR3mediated signaling during viral infection protects against demyelinating disease by reducing the viral load. In contrast, premature activation of TLR3 signal transduction prior to viral infection may induce premature stimulation of regulatory immune mechanisms, hindering antiviral immune cell function and promoting viral persistence.

\section{Additional material}

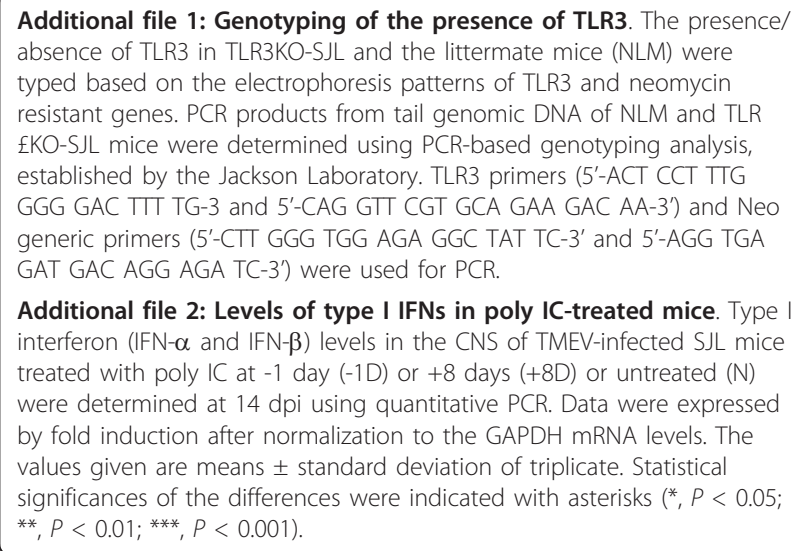

Additional file 2: Levels of type I IFNs in poly IC-treated mice. Type interferon (IFN- $\alpha$ and IFN- $\beta$ ) levels in the CNS of TMEV-infected SJL mice treated with poly IC at -1 day $(-1 \mathrm{D})$ or +8 days $(+8 \mathrm{D})$ or untreated $(\mathrm{N})$ were determined at 14 dpi using quantitative PCR. Data were expressed by fold induction after normalization to the GAPDH mRNA levels. The values given are means \pm standard deviation of triplicate. Statistical significances of the differences were indicated with asterisks $\left({ }^{*}, P<0.05\right.$; **, $\left.P<0.01 ;{ }^{* *}, P<0.001\right)$.

\section{Abbreviations}

TLR3: toll-like receptor-3; MS: multiple sclerosis; CNS: central nervous system; dpi: days post-infection; PFU: plaque forming units; RT-PCR: reverse transcriptase-polymerase chain reaction; TMEV: Theiler's murine encephalomyelitis virus.

\section{Acknowledgements}

This work was supported by a United States Public Health Service Grant (RO1 NS28752) and by a grant from the National Multiple Sclerosis Society (RG 4342-A7).

\section{Author details}

${ }^{1}$ Department of Microbiology-Immunology, Northwestern University Medical School, Chicago, Illinois 60611, USA. ²Department of Pathology, Graduate School of Medicine, Shinshu University, Matsumoto, Nagano 390-8621, Japan. ${ }^{3}$ Biomedical Laboratory Sciences, Graduate School of Medicine, Shinshu University, Matsumoto, Nagano 390-8621, Japan.

\section{Authors' contributions}

YHJ and MHK investigated disease development. YHJ performed immunological studies and contributed to writing the manuscript. HSK generated peptide-loaded tetramers. TK and CSK performed histological studies and contributed to analysis. CSK and BSK analyzed the data and 
wrote the manuscript. All authors have seen and approved the final version of the manuscript.

\section{Competing interests}

The authors declare that they have no competing interests.

Received: 12 October 2011 Accepted: 21 December 2011 Published: 21 December 2011

\section{References}

1. Akira S, Hoshino K, Kaisho T: The role of Toll-like receptors and MyD88 in innate immune responses. J Endotoxin Res 2000, 6:383-387.

2. Guillot L, Le Goffic R, Bloch S, Escriou N, Akira S, Chignard M, Si-Tahar M: Involvement of toll-like receptor 3 in the immune response of lung epithelial cells to double-stranded RNA and influenza A virus. J Biol Chem 2005, 280:5571-5580.

3. Alexopoulou L, Holt AC, Medzhitov R, Flavell RA: Recognition of doublestranded RNA and activation of NF-kappaB by Toll-like receptor 3. Nature 2001, 413:732-738

4. Kawai T, Akira S: Toll-like receptors and their crosstalk with other innate receptors in infection and immunity. Immunity 2011, 34:637-650.

5. Zhang SY, Jouanguy E, Ugolini S, Smahi A, Elain G, Romero P, Segal D, Sancho-Shimizu V, Lorenzo L, Puel A, et al: TLR3 deficiency in patients with herpes simplex encephalitis. Science 2007, 317:1522-1527.

6. Daffis S, Samuel MA, Suthar MS, Gale M Jr, Diamond MS: Toll-like receptor 3 has a protective role against West Nile virus infection. J Virol 2008, 82:10349-10358.

7. Richer MJ, Lavallee DJ, Shanina I, Horwitz MS: Toll-like receptor 3 signaling on macrophages is required for survival following coxsackievirus B4 infection. PLOS One 2009, 4:e4127.

8. Tabeta K, Georgel P, Janssen E, Du X, Hoebe K, Crozat K, Mudd S, Shamel L, Sovath S, Goode J, et al: Toll-like receptors 9 and 3 as essential components of innate immune defense against mouse cytomegalovirus infection. Proc Natl Acad Sci USA 2004, 101:3516-3521.

9. Le Goffic R, Balloy V, Lagranderie M, Alexopoulou L, Escriou N, Flavell R, Chignard M, Si-Tahar M: Detrimental contribution of the Toll-like receptor (TLR)3 to influenza A virus-induced acute pneumonia. PLOS Pathog 2006, 2:e53.

10. Edelmann $\mathrm{KH}$, Richardson-Burns $\mathrm{S}$, Alexopoulou $\mathrm{L}$, Tyler $\mathrm{KL}$, Flavell RA, Oldstone MB: Does Toll-like receptor 3 play a biological role in virus infections? Virology 2004, 322:231-238.

11. Wang T, Town T, Alexopoulou L, Anderson JF, Fikrig E, Flavell RA: Toll-like receptor 3 mediates West Nile virus entry into the brain causing lethal encephalitis. Nat Med 2004, 10:1366-1373.

12. Pevear DC, Calenoff M, Rozhon E, Lipton HL: Analysis of the complete nucleotide sequence of the picornavirus Theiler's murine encephalomyelitis virus indicates that it is closely related to cardioviruses. J Virol 1987, 61:1507-1516.

13. Lipton HL, Dal Canto MC: Chronic neurologic disease in Theiler's virus infection of SJL/J mice. J Neurol Sci 1976, 30:201-207.

14. Dal Canto MC, Lipton HL: Multiple sclerosis. Animal model:Theiler's virus infection in mice. Am J Path 1977, 88:497-500.

15. Dal Canto MC, Kim BS, Miller SD, Melvold RW: Theiler's murine encephalomyelitis virus (TMEV)-induced demyelination: a model for human multiple clerosis. Methods 1996, 10:453-461.

16. So EY, Kang MH, Kim BS: Induction of chemokine and cytokine genes in astrocytes following infection with Theiler's murine encephalomyelitis virus is mediated by the Toll-like receptor 3. Glia 2006, 53:858-867.

17. So EY, Kim BS: Theiler's virus infection induces TLR3-dependent upregulation of TLR2 critical for proinflammatory cytokine production. Glia 2009, 57:1216-1226.

18. Suh HS, Brosnan CF, Lee SC: Toll-like receptors in CNS viral infections. Curr Top Microbiol Immunol 2009, 336:63-81.

19. Olson JK, Miller SD: Microglia initiate central nervous system innate and adaptive immune responses through multiple TLRs. J Immunol 2004, 173:3916-3924.

20. Turrin NP: Central nervous system Toll-like receptor expression in response to Theiler's murine encephalomyelitis virus-induced demyelination disease in resistant and susceptible mouse strains. Virol J 2008, 5:154.
21. Hou W, So EY, Kim BS: Role of dendritic cells in differential susceptibility to viral demyelinating disease. PLoS Pathog 2007, 3:e124.

22. Jin $\mathrm{YH}$, Mohindru M, Kang MH, Fuller AC, Kang B, Gallo D, Kim BS: Differential virus replication, cytokine production, and antigenpresenting function by microglia from susceptible and resistant mice infected with Theiler's virus. J Virol 2007, 81:11690-11702.

23. Kang MH, So EY, Park H, Kim BS: Replication of Theiler's virus requires NFkappaB-activation: higher viral replication and spreading in astrocytes from susceptible mice. Glia 2008, 56:942-953.

24. Kato $H$, Takeuchi $O$, Sato S, Yoneyama M, Yamamoto M, Matsui $K$, Uematsu S, Jung A, Kawai T, Ishii KJ, et al: Differential roles of MDA5 and RIG-I helicases in the recognition of RNA viruses. Nature 2006, 441:101-105

25. Pichlmair A, Schulz O, Tan CP, Rehwinkel J, Kato H, Takeuchi O, Akira S, Way M, Schiavo G, Reis e Sousa C: Activation of MDA5 requires higherorder RNA structures generated during virus infection. J Virol 2009, 83:10761-10769.

26. Jin YH, Hou W, Kim SJ, Fuller AC, Kang B, Goings G, Miller SD, Kim BS: Type I interferon signals control Theiler's virus infection site, cellular infiltration and T cell stimulation in the CNS. J Neuroimmunol 2010, 226:27-37.

27. Biron CA: Interferons alpha and beta as immune regulators-a new look. Immunity 2001, 14:661-664.

28. Herbst-Kralovetz MM, Pyles RB: Quantification of poly(l:C)-mediated protection against genital herpes simplex virus type 2 infection. J Virol 2006, 80:9988-9997.

29. Gibbert K, Dietze KK, Zelinskyy G, Lang KS, Barchet W, Kirschning CJ, Dittmer U: Polyinosinic-polycytidylic acid treatment of Friend retrovirusinfected mice improves functional properties of virus-specific $T$ cells and prevents virus-induced disease. J Immunol 2010, 185:6179-6189.

30. Wedekind D, Weiss H, Jorns A, Lenzen S, Tiedge M, Hedrich HJ: Effects of polyinosinic-polycytidylic acid and adoptive transfer of immune cells in the Lew.1AR1-iddm rat and in its coisogenic LEW.1AR1 background strain. Autoimmunity 2005, 38:265-275.

31. Dogusan Z, Garcia M, Flamez D, Alexopoulou L, Goldman M, Gysemans C, Mathieu C, Libert C, Eizirik DL, Rasschaert J: Double-stranded RNA induces pancreatic beta-cell apoptosis by activation of the toll-like receptor 3 and interferon regulatory factor 3 pathways. Diabetes 2008, 57:1236-1245.

32. Ren X, Zhou H, Li B, Su SB: Toll-like receptor 3 ligand polyinosinic: polycytidylic acid enhances autoimmune disease in a retinal autoimmunity model. Int Immunopharmacol 2011, 11:769-773.

33. Pullen LC, Park SH, Miller SD, Dal Canto MC, Kim BS: Treatment with bacterial LPS renders genetically resistant $\mathrm{C} 57 \mathrm{BL} / 6$ mice susceptible to Theiler's virus-induced demyelinating disease. J Immunol 1995, 155:4497-4503.

34. Theiler M: Spontaneous encephalomyelitis of mice: a new virus disease. $J$ Exp Med 1937, 65:705-719.

35. Hou W, Kang HS, Kim BS: Th17 cells enhance viral persistence and inhibit T cell cytotoxicity in a model of chronic virus infection. J Exp Med 2009, 206:313-328.

36. Keir ME, Butte MJ, Freeman GJ, Sharpe AH: PD-1 and its ligands in tolerance and immunity. Annu Rev Immunol 2008, 26:677-704.

37. Pulko V, Liu X, Krco CJ, Harris KJ, Frigola X, Kwon ED, Dong H: TLR3stimulated dendritic cells up-regulate $\mathrm{B} 7-\mathrm{H} 1$ expression and influence the magnitude of CD8 T cell responses to tumor vaccination. J Immunol 2009, 183:3634-3641.

38. He H, Messer RJ, Sakaguchi S, Yang G, Robertson SJ, Hasenkrug KJ: Reduction of retrovirus-induced immunosuppression by in vivo modulation of T cells during acute infection. J Virol 2004, 78:11641-11647.

39. Boettler T, Spangenberg HC, Neumann-Haefelin C, Panther E, Urbani S, Ferrari C, Blum HE, von Weizsacker F, Thimme R: T cells with a CD4+CD25 + regulatory phenotype suppress in vitro proliferation of virus-specific CD8+ T cells during chronic hepatitis C virus infection. J Virol 2005, 79:7860-7867.

40. Zelinskyy G, Kraft AR, Schimmer S, Arndt T, Dittmer U: Kinetics of CD8+ effector T cell responses and induced CD4+ regulatory $T$ cell responses during Friend retrovirus infection. Eur J Immunol 2006, 36:2658-2670.

41. Sehrawat S, Suvas S, Sarangi PP, Suryawanshi A, Rouse BT: In vitrogenerated antigen-specific CD4+ CD25+ Foxp3+ regulatory $T$ cells control the severity of herpes simplex virus-induced ocular immunoinflammatory lesions. J Virol 2008, 82:6838-6851. 
42. Richards MH, Getts MT, Podojil JR, Jin YH, Kim BS, Miller SD: Virus expanded regulatory $\mathrm{T}$ cells control disease severity in the Theiler's virus mouse model of MS. J Autoimmun 2011, 36:142-154.

43. Schulz O, Pichlmair A, Rehwinkel J, Rogers NC, Scheuner D, Kato H, Takeuchi O, Akira S, Kaufman RJ, Reis e Sousa C: Protein kinase R contributes to immunity against specific viruses by regulating interferon mRNA integrity. Cell Host Microbe 2010, 7:354-361.

44. Doedens JR, Kirkegaard K: Inhibition of cellular protein secretion by poliovirus proteins $2 B$ and $3 A$. EMBO J 1995, 14:894-907.

45. Fiette L, Aubert C, Muller U, Huang S, Aguet M, Brahic M, Bureau JF: Theiler's virus infection of $129 \mathrm{~Sv}$ mice that lack the interferon alpha/ beta or interferon gamma receptors. Journal of Experimental Medicine 1995, 181:2069-2076.

46. Jin YH, Kim SJ, So EY, Meng L, Colonna M, Kim BS: Melanoma differentiation-associated gene 5 is critical for protection against Theiler's virus-induced demyelinating disease. J Virol 2011.

47. Richmond JY, Hamilton LD: Foot-and-mouth disease virus inhibition induced in mice by synthetic double-stranded RNA (polyriboinosinic and polyribocytidylic acids). Proc Natl Acad Sci USA 1969, 64:81-86.

48. Rouse BT, Sarangi PP, Suvas S: Regulatory T cells in virus infections. Immunol Rev 2006, 212:272-286.

doi:10.1186/1742-2094-8-178

Cite this article as: Jin et al:: TLR3 signaling is either protective or pathogenic for the development of Theiler's virus-induced demyelinating disease depending on the time of viral infection. Journal of Neuroinflammation 2011 8:178.

\section{Submit your next manuscript to BioMed Central and take full advantage of:}

- Convenient online submission

- Thorough peer review

- No space constraints or color figure charges

- Immediate publication on acceptance

- Inclusion in PubMed, CAS, Scopus and Google Scholar

- Research which is freely available for redistribution

Submit your manuscript at www.biomedcentral.com/submit 